\title{
MISTRAL MISTRAL
}

Journal of Latin American Women's

Intellectual \& Cultural History

\section{SONAR WILDLY: Una escritura geológica de Gloria Anzaldúa}

\section{Cristina Rivera Garza}

To cite: Cristina Rivera Garza. 2021. "SONAR WILDLY: Una escritura geológica de Gloria Anzaldúa." Mistral: Journal of Latin American Women's Intellectual \& Cultural History 1 (1): 1-11, https://doi.org/ 10.21827/mistral.1.37552. 


\title{
SONAR WILDLY: Una escritura geológica de Gloria Anzaldúa
}

\author{
Cristina Rivera Garza
}

\section{HIJAS DEL ALGODÓN}

A inicios de marzo del 2020, apenas unos días después de que cundiera la alerta que provocó el primer anuncio de la presencia del virus COVID-19 en Texas, condujimos hasta la frontera para llevar a mi madre de regreso a México. Preparamos todo con calma, como si se tratara de otro viaje más, pero íbamos serios en el camino, observando el paisaje del valle con ojos pasmados. De reojo, mientras capturaba algunos gestos de mi madre en el espejo retrovisor, me preguntaba cuántas veces no habíamos recorrido ya esta carretera y si lo volveríamos a hacer en alguna otra ocasión en el futuro. Juntas. ¿Sería ésta nuestra última vez? El primer viaje que mi madre hizo unos 50 años atrás había seguido la misma ruta, pero al revés: de Brownsville a Houston, en tren. De repente, esa muchacha joven, de extraordinarios ojos grandes y cejas tupidas, se detenía en el reflejo a medias curiosa, a medias fastidiada por las horas en el camino. ¿Ya vamos a llegar? A su lado venía su hermana Santos, platicando sin cesar, tomándole la mano de cuando en cuando. Ahí, en el asiento de atrás, cuchicheando entre risas como si fueran adolescentes, juntaban unos 160 años de experiencia entre las dos. Te acuerdas de. Érase que se era. Fíjate que. El calor apretaba el tallo de los árboles y caía, pesado, sobre los matorrales. El calor diluía el color de los autos y producía esa sensación de espejismo hacia el final de la carretera. Todavía no era ni primavera y ya se cernía esa luz densa, llena de humedad, sobre la planicie. El verde de los matorrales y el verde de los mezquites se confundía con el verde de los zacates. En lo alto, un azul celeste borraba todo lo demás. Nos detuvimos en Refugio para poner gasolina y comer algo y ahí, al consultar el GPS, siguiendo el recorrido de la carretera 69E hacia el sur, reconocí el nombre: en unas dos horas y media pasaríamos a un lado de Raymondville. ¿Te acuerdas?, le pregunté a Saúl mostrándole la pantalla del teléfono. Quedamos de parar por ahí alguna vez, añadí. Deberíamos hacerlo, dijo sin chistar. Deberíamos, nos contestó el viento que combaba las palmeras del camino.

Estábamos entrando ya en la vereda tropical texana, la punta del sur del estado que incluye unos 20 condados y colinda, al sur, con la frontera y, al este, con el golfo de México. La vegetación se volvió un poco más exuberante de súbito. Un verde más pálido, un poco más brillante también, emanaba de hojas grandes que alcanzaban a producir sombra a los costados del camino. Nada en lo que veíamos, sin embargo, hacía presentir lo que había existido antes. O lo que todavía estaba aquí, oculto bajo capas de tiempo. Apenas unos cuantos siglos atrás, cuando iniciaron las primeras exploraciones del área un poco después de la conquista, esta zona tropical hecha de una infinidad de microclimas estuvo cubierta por un denso bosque ribereño. Árboles de distintas alturas, enredaderas muy tupidas y espesos arbustos espinosos habían cercado los pantanos que anunciaban el agua. Boscajes de palmas. Matorrales. Entre más avanzábamos, más se dejaba sentir el río en el ambiente. Hacia allá íbamos. Eso era lo que, en un par de días, cruzaríamos juntas. El Río de Las Palmas o el Gran Río del Norte, como le decían los que lo vieron por primera vez. El río que nosotras conocimos siempre como el Río Bravo, aunque nuestros parientes del otro lado lo 
llamaran el Río Grande. Ese caudal, ese lento humedecer de la tierra. Una cuenca siempre en movimiento. Las llanuras de su propia inundación. Ese fluir de agua dulce y minerales y tiempo, repartido en tantos brazos y afluentes, definió la infancia de mi madre y sus hermanas. Sus aguas, derramadas a través de un curioso sistema de diques y bordos, alimentaron las raíces de las matas de algodón que transformaron radicalmente su vida en la frontera. Se trata, sin duda, del río de nuestras vidas.

¿Por qué nos detenemos aquí?, preguntó mi madre. ¿Pasa algo? Estábamos a la entrada de Raymondville, frente a un viejo granero de altos techos de dos aguas, ambos oxidados por el paso tiempo. Los altos postes de la electricidad. La vía del tren. Aquí nació una mujer a la que les habría gustado conocer, les dije. Saúl se bajó del auto para sacar a caminar a Lara, la perrita que se había convertido en el centro de nuestra atención después de pasar apenas un par de meses con nosotros, y para tomar algunas fotos. Se llamó Gloria Anzaldúa, añadí, contorsionando la espalda para poder verlas de frente en el asiento de atrás. Tendría más o menos su edad, le dije a mi madre, que nació en 1943. También en el signo de libra. Y era muy argüendera, añadí guiñándoles un ojo, como ustedes. Fue en ese momento que decidimos que de verdad tendríamos que detenernos en este lugar y, por eso, arrancamos el auto, pensando que lo haríamos con más calma en el viaje de regreso.

Nuestro destino final era Reynosa, de donde saldría el avión que llevaría a mi madre al centro de México, pero antes teníamos planeado pasar un par de días conviviendo con dos más de sus hermanas en Brownsville. Además de Santos, la que ha vivido en Houston por ya casi 60 de sus 82 años, pronto encontraríamos a Yolanda, quien llevaba tiempo disfrutando su retiro en un pequeño departamento cerca de la Isla del Padre, y a Esthela, que se había asentado, ya también por años, en un vaivén entre Brownsville a Matamoros, y Brownsville otra vez. Todas ellas, incluso las dos hermanas que no pudieron llegar a esta cita apresurada antes del despliegue de la pandemia, eran hijas del Río Bravo, e hijas del Río Grande Valley, del valle de Matamoros. Todas son hijas del algodón.

\section{TIERRAS Y PRÉSTAMOS}

Se le llamó, por mucho tiempo, la llanura costera del golfo, aunque también fue conocida como Las tierras bajas costeras del golfo. El delta del Río Bravo abarcaba desde el río San Fernando en el norte de Tamaulipas, hasta el río Nueces, en el sur de Texas: unos 322 kilómetros atravesados por las cordilleras de la Sierra Madre Oriental. Una barra de casi 137 kilómetros arriba de la desembocadura del río, y una Laguna Madre dividida en dos. El viento del sureste por sobre todo eso. Gloria Anzaldúa nació en Raymondville, en efecto, en esa triangular piece of land wedged between the river and the golfo which serves as the Texas-U.S. / Mexican border. ${ }^{1}$ Aquí creció y de aquí se fue, the first in six generations to leave the Valley, the only one in my family to ever leave home. ${ }^{2}$ Fue, desde chica, una terca; una floja que prefería leer o andar de un lado para otro en lugar de plancharle las camisas a sus hermanos o limpiar los trinchadores. Nunca supo inclinarse ante las órdenes del padre o de la religión y, mejor, se fue a abrir camino por otro lado. Pronto tuvo que aceptar, felizmente, que era una andariega, tal como se lo habían advertido. ¿Te gusta la mala vida?

\footnotetext{
${ }^{1}$ Gloria Anzaldúa, Borderlands / La frontera. The New Mestiza (Aunt Lute Books, 1987), 35.

${ }^{2}$ Anzaldúa, Borderlands, 16.
} 
Como las hermanas de mi madre, Gloria fue testigo de la transformación agrícola del Valley a mediados del siglo XX. Después de los tratados de Guadalupe Hidalgo que declararon en 1848 que en el centro del Río Bravo flotaba la línea que, a partir de entonces, separaría a los dos países; después de la gradual pero mortífera desposesión de las tierras, que fue luego asegurada por medio de los linchamientos que sembraron el terror entre mexicanos y chicanos; después, en los 1930s, llegaron las grandes corporaciones agrícolas a contratar a trabajadores mexicanos para desbrozar la tierra a punto de sudor y de machete. Así se tendieron las bases del sistema de irrigación en ese pedazo de vereda tropical, estepa y desierto en el sur más septentrional de Texas. Una década más tarde, Gloria Anzaldúa fue testigo del fin de la agricultura de temporal y del reordenamiento geométrico de la tierra in neat rectlangles and squares en los que la temporada de siembra y la de cosecha se llevaba a cabo ininterrumpidamente los 365 días del año.

Fue por entonces que don Urbano Anzaldúa, el padre de Gloria y un nativo del lugar, tuvo que convertirse en sharecropper para mantener a su familia, aceptando préstamos de la Río Farms Incorporated que, llegado el momento de la cosecha, tenía que regresar con creces. Casi todos los miembros de la familia trabajaron en algún punto en las granjas agrícolas donde vivían, la de King Ranch, por ejemplo, que incluía una granja de leche; y en una granja de pollos, cuyas plumas blancas blanketed the land for acres around. ${ }^{3}$ Mientras tanto, del otro lado de la frontera, Don Cristino Garza Peña, un deportado de los Estados Unidos que había llegado a la Colonia 18 de Marzo junto con su esposa y su creciente familia, se convertía por primera vez en dueño de un pedazo de tierra gracias al reparto agrario que organizó el gobierno de Lázaro Cárdenas en la frontera noreste de México. ${ }^{4}$ No era un nativo de la región, sino un inmigrante. Un invitado. No le urgía irse de aquí, sino encontrar una manera de quedarse. Y, para que eso fuera posible, se dejaba refaccionar con préstamos que, en su caso, provenían del estado, a través del Banco Ejidal, que también tenía que pagar, con creces, en el momento de la cosecha. Mientras tanto, a lo largo del año, trabajaba duro barbechando la tierra, preparando los canales de riego, rociando los fertilizantes sobre los surcos, hasta que los capullos del algodón estaban listos para las manos de los pizcadores. Una vez organizado en pacas, el algodón terminaba cruzando el río en su camino hacia el mercado de exportación.

Aunque dividido por una línea fronteriza, el valle o el Río Grande Valley compartía modos de producir y de vivir, modos de deber la vida, de vivir de crédito, que traían consigo, sin embargo, grados distintos de sujeción y de desposesión. El lado estadounidense del Río Bravo se benefició con mucha anterioridad de los escurrimientos del río, pero cuando el gobierno mexicano pudo asegurar acceso al agua después de innumerables negociaciones en comisiones internacionales, ambos costados de la frontera desarrollaron un sistema de vida alrededor de la siembra y cosecha del algodón. Hubo, por algunas décadas, un crecimiento económico inaudito y una movilidad social nunca antes vista en la región. Hubo innumerables madrugadas en las que había que irse al campo antes de que cayera el sereno. Hubo casas de madera, plazas donde se veían de reojo los que se cortejaban, salones de baile. Hubo bancos, gines donde se procesaba el algodón, brechas. Y hubo, también, formas de crecer, sobre todo de convertirse en mujer, que resultaron cada vez más exiguas, cada vez más asfixiantes.

\footnotetext{
${ }^{3}$ Anzaldúa, Borderlands, 9.

${ }^{4}$ Una versión ampliada de esta historia sirvió de base para Autobiografía del algodón (Random House, 2020).
} 


\section{VÍBORAS}

En el ya paradigmático Borderlands. La frontera. The New Mestiza, Gloria Anzaldúa cuenta cómo reconoció a su nahual y le creció la conciencia al mismo tiempo. Ocurrió en la intemperie, mientras ella estaba chopping cotton, tratando de deshacerse del quelite con un gran azadón. La víbora la mordió, pero los colmillos se atoraron en la bota de trabajo antes de inocular su veneno. La madre de Gloria llegó pronto y, con su hoe, mató al animal, partiéndolo en dos. Ya sola en medio del campo, Gloria sacó su pocket knife y marcó con una X cada prick. Luego, sorbió la sangre del suelo y la escupió entre el algodonal. ${ }^{5}$ De entre los muchos nacimientos y rebeldías que Anzaldúa relata en su libro bilingüe, también reacio a aceptar las reglas dictadas por una supuesta pureza del lenguaje, me quedo con esta escena. Aquí está ella, joven y testaruda, reaccionando a toda prisa, tanto física como espiritualmente, ante los elementos intrínsecos del Valley con los dos pies bien plantados sobre la tierra. Aquí, a un costado de la carretera por la que manejábamos ese inicio de marzo, Gloria se descubría para siempre inmune contra el veneno de los distintos tipos de terrorismo -íntimo, lingüístico, de género - que habría de enfrentar a lo largo de su vida.

Como Gloria del lado gringo de la línea, las hermanas de mi madre crecieron en el torbellino de esa cultura de la tiranía que establecía lugares estrechos, y muy estrechamente vigilados, para las mujeres. Tenían pocas alternativas de vida: casarse y tener hijos, como lo hizo la hermana mayor; estudiar mecanografía y taquigrafía, trabajar un tiempo antes de casarse y tener hijos, como lo hizo mi madre; o migrar a los Estados Unidos, como lo hicieron dos de sus hermanas: una para casarse y tener hijos, y otra para trabajar y casarse y divorciarse y formar parte del movimiento chicano que conmovió a Houston en los 1960s.

El mandato del silencio y la obediencia constituía, sin duda, la base no dicha, pero igualmente inescapable, de su día a día. Algunas lo aceptaron, apenas sin chistar, pero otras se convirtieron en hociconas, repelonas y chismosas. A diferencia de Gloria que, del lado texano, hablaba en sus native tongues, que eran al menos cinco, entre ellas el standard Mexican Spanish, el north Mexican Spanish dialect, el Chicano Spanish (con las variaciones entre Texas, New Mexico, Arizona and California), el Tex-Mex, y el pachuco (también conocido como caló), las hermanas de mi madre abrieron el silencio, a veces de golpe y a veces poco a poco, como si temieran despertar fantasmas, con un español fronterizo que, sin llegar a ser Spanglish propiamente, contaba a wachar o parquear entre sus verbos más cotidianos. ${ }^{6}$ No era el español estándar que se diseminaba a través de una enseñanza pública diseñada en oficinas desde la Ciudad de México pero, aunque vivían justo a unos quince kilómetros del caudal mayor del Bravo, tampoco era el caló de los pachucos. Más que norteño, sí era un español eminentemente fronterizo, tanto en la enunciación como en la selección del vocabulario. Además de algunas palabras en inglés, las contracciones recurrentes y el ritmo de las oraciones indicaban que algo estaba a punto de convertirse en otra cosa. Algo terminaba y, al mismo tiempo, empezaba ya.

Mientras Gloria enfrentaba escuelas segregadas del otro lado, así como diversas formas del terrorismo lingüístico que, hasta hoy en día, denigra el uso del español y sus variantes, las hermanas de mi madre recorrían unos cinco kilómetros de veredas, con el lonche calientito en contenedores de estaño, para ir del rancho de la familia hasta la casa de madera que cumplía las veces de escuela rural, donde una maestra solitaria les enseñaba a leer y escribir, hacer cuentas. En esos años de la niñez, mientras las corporaciones incursionaban con saña en las tierras que mojaba el Río Bravo, las muchachas se acostumbraron a tomar leche bronca y dormir temprano, a comer

\footnotetext{
${ }^{5}$ Anzaldúa, Borderlands, 26.

${ }^{6}$ Anzaldúa, Borderlands, 55-56.
} 
calabacitas recién cosechadas de la hortaliza y a romper las sandías del verano contra el suelo para elegir así el mejor pedazo. No tenían que hacer otra cosa más que elegir una gallina del corral para comer carne algún día. Tal vez por eso las que eventualmente se fueron, las que terminaron por dejar los campos de algodón atrás, tardaron más tiempo en irse.

Gloria Anzaldúa definió a la frontera como una herida abierta, ese lugar donde se adhieren las costras de lastimaduras que intentamos cerrar una y otra vez sin lograr sanarlas del todo. La excoriación provocada por la desigualdad de género no es menor entre todas las demás: las relaciones entre hombres y mujeres de uno y otro lado del Río Bravo no han cambiado mucho desde que Gloria emprendió su camino hacia el norte de California. Incluso ahora, cuando nos acercamos a esos pueblos fronterizos donde crecieron mi madre y sus hermanas, suelo hacerlo con mucho cuidado, tentativamente, y nunca sin ver todo desde lejos primero. Los hombres hacen las reglas y las leyes, decía Anzaldúa, pero las mujeres las transmiten. Y en una tierra de machismos acendrados y obediencias sin disputa, las críticas más acérrimas pueden provenir de hombres y mujeres comprometidos por igual con el status quo. La mordedura de las víboras no siempre produce conciencia, pero sí daño.

Si hubiera leído a Anzaldúa antes, cuando mi relación con las tierras de la frontera tamaulipeca apenas tomaba su forma propia, tal vez no habría decidido alejarme con una obstinación tan férrea de un lugar en el que apenas viví un par de años. Por mucho tiempo creí que había rechazado todo del valle - sus cuentos de fantasmas, las zambullidas en los diques de riego, el campo abierto - cuando en realidad sólo me resistí con todo lo que tenía a la mano contra la camisa de fuerza que ataba a las mujeres con una crueldad inaudita. No quería la dictadura del trabajo doméstico ni la regla del silencio ni el calabozo silencioso de la sexualidad. No quería sus domingos de misa ni la supeditación al padre ni las miradas torvas que se deslizaban, pegajosas, sobre todo lo diferente. No quería la palabra de dios. No quería la palabra del diablo. Cuando el libro de Anzaldúa llegó a mis manos, tal vez demasiado tarde, ya cuando preparaba mis exámenes comprensivos para el doctorado, entendí por fin que la rebeldía también era el nombre de otra de las tradiciones de la tierra en que había nacido. Y eso sí lo quise: la lengua bífida, la escritura, el retorno (por otros medios).

\section{COMECRUDOS Y VIAJANSOLOS}

Tal vez la exploración más famosa de lo que ahora se conoce como el norte de Tamaulipas y Nuevo León fue la caminata que emprendió Alvar Núñez Cabeza de Vaca después de naufragar en el golfo y, luego, escapar de sus captores en $1535 .^{7}$ Aunque la geografía del recorrido todavía despierta discusiones apasionadas, es comúnmente aceptado que Cabeza de Vaca partió de la costa del sur de Texas, cruzó el Río Bravo más o menos por donde hoy se encuentra Reynosa, y atravesó a pie todo el trecho que le faltaba para alcanzar el océano Pacífico. En Naufragios, la relación que preparó para la Corona cuando ya se había convertido en el gobernador de Paraguay, Cabeza de Vaca registró algunos de los nombres de los pueblos indígenas con los que convivió en el costado norte del río, pero ninguno de los que encontró hacia el sur del mismo. Igualmente, las exploraciones que se llevaron a cabo en el siglo XVI fueron cuidadosas en dejar por sentado la cantidad de nativos que habitaban el área, pero ninguno de ellas tomó nota de los nombres de sus habitantes. No fue sino hasta mediados del siglo XVIII, cuando José de Escandón exploró y

\footnotetext{
${ }^{7}$ Alvar Núñez Cabeza de Vaca, Naufragios, edición de Juan Francisco Maura (Cátedra, 2007).
} 
colonizó lo que en su momento se llamó Nuevo Santander que esos nombres empezaron a salir a la luz. ${ }^{8}$

Uno de los aproximadamente 40 pueblos indígenas que documentó Escandón en los reportes que le envió a la Corona entre 1747 y 1757 se llamaba Como se llama. Otro: los Anda en camino. Otro: Los que viajan solos. Uno más, tal vez el pueblo más numeroso: los Comecrudo. ${ }^{9}$ Según los cálculos que hizo desde su campamento base, que se encontraba cerca de donde hoy está Matamoros, en el área existían unas 2,500 familias, es decir, unas 15,000 personas distribuidas en rancherías más o menos temporales en las riberas del río. Vivían, casi todos, de la caza, la pesca y la recolección, y habitaban en chozas de carrizo abiertas a los elementos. Así, aunque el noreste mexicano insista en un pasado libre de pueblos indígenas, o uno en que todos ellos fueron arrasados por enfermedades y violencia en los años inmediatos a la conquista, Martín Salinas Rivera provee evidencias para argumentar justamente lo contrario. En Indígenas del Delta del Río Bravo, Salinas elabora complejas listas con los nombres y los números asociados a un nutrido contingente de pobladores indígenas de lo que hoy es el norte de Tamaulipas y Nuevo León. Queda claro entonces que es del todo posible elaborar una genealogía indígena desde la desembocadura del Río Bravo.

Decía Ricardo Pigilia en relación a Borges, aunque en realidad en relación a todo escritor, que la elaboración alrededor del origen, la clarificación para sí sobre el legado del que parte y el que, por lo tanto, trae consigo a la literatura, era un paso fundamental para todo proyecto de escritura. En muchos sentidos, en Borderlands, Gloria Anzaldúa se dedica con especial ahínco a rehacer esa genealogía tanto personal como comunitaria, ubicándola metafórica y empíricamente en una geografía específica - la frontera-y colocando ahí, en su propio centro y de manera preponderante al pasado indígena que reconoce como propio: el de los Aztecas. Son ellos los que, en tanto migrantes, llegan al sureste de lo que es ahora los Estados Unidos con las primeras olas de presencia humana en el continente y los que luego lo abandonan, hacia $1168 \mathrm{AD}$, para fundar, en el sitio donde encuentran un águila sobre un nopal devorando una serpiente, la Ciudad de México. ¿Qué habría pasado, me pregunto, si en lugar de recurrir a la sociedad más poderosa y vertical de Mesoamérica, que eventualmente se convirtió en la referencia privilegiada del estado mexicano, Anzaldúa hubiera reclamado para sí a los Comecrudo y los Anda el Camino del Delta del Bravo, esa cuchilla de tierra donde nació y creció y de la que luego se fue?

La visión de los vencidos, la colección de fuentes primarias indígenas que tradujo Miguel León-Portilla se publicó por primera vez en $1959 .{ }^{10}$ Unos cinco años después, Charles Gibson dio a conocer su monumental The Aztecs Under Spanish Rule, un estudio destallado, basado en análisis de un amplio rango de fuentes primarias, que en mucho contribuyó a problematizar visiones simplistas del imperio azteca y de Mesoamérica antes y después de la intervención de los españoles. ${ }^{11}$ Mientras Anzaldúa preparaba ese peculiar libro filosófico y autobiográfico que es Borderlands, los estudiosos de las sociedades mesoamericanas abrían el terreno para discutir el papel de las epidemias y la violencia genocida de la conquista, que arrasaron con la población de las Américas hasta en un 90 por cierto, así como la agencia indígena - no sólo de los aztecas, sino también, entre otros, de los tlaxcaltecas - en el contexto del surgimiento de un buen número de rebeliones locales durante el proceso. De este modo, al reclamar para sí, de entre todos los legados

\footnotetext{
${ }^{8}$ Martín Salinas Rivera, Indígenas del Delta del Río Bravo. Su papel en la historia del sur de Texas y el noreste de México, traducción de Elena de Albuerne (Universidad Autónoma de Tamaulipas, 2012).

${ }^{9}$ Salinas, Indígenas del Delta del Río Bravo, 81.

${ }^{10}$ Miguel León-Portilla, La visión de los vencidos. Relaciones indígenas de la conquista (UNAM, 2007).

${ }^{11}$ Charles Gibson, The Aztecs Under Spanish Rule. A History of the Indians of the Valley of Mexico from 1519-1810 (Stanford University Press, 1964).
} 
indígenas, el de los Aztecas, Anzaldúa llevó a cabo una operación arriesgada y definitoria a la vez. Como una buena curandera, identificó y, al hacerlo, activó las fuentes de poder más acendradas y, en lugar de confirmarlas en su propia estructura piramidal y mortífera, las subvirtió al enfatizar el territorio de su propia enunciación. No por nada, Borderlands inicia descifrando la relevancia histórica y política, siempre mutante pero estructural, de una ubicación-que es a la vez material y espiritual - muy precisa: la frontera. Invocar al poderío azteca desde ahí, desde el territorio hostil donde enfrentaba, en tanto persona y en tanto comunidad, los terrorismos distintos de la colonialidad, trastocaba de inmediato lo invocado. Aunque parecen idénticos, ni su Coatlicue ni su Coaxihuitl, ni su tlapalli son los mismos que el estado mexicano ha apropiado al contarse a sí mismo como la culminación de una continuidad que surge a partir de la fundación de Tenochtitlán. Por eso, para los que crecimos en México, esa invocación del legado azteca es mucho más complicada. La apropiación estatal de la sociedad Mexica, su centralidad en conceptos de nación y jerarquizaciones señeras de raza, clase y género, deja poco espacio para el trastocamiento que, desde la perspectiva de Anzaldúa, es concomitante al espacio fronterizo. Para luchar contra dualidades sin salida e incorporar tradiciones de rebelión indígena en genealogías propias y colectivas es mejor regresar al terruño y escarbar ahí. ¿Qué terruño bien estudiado no es un espacio fronterizo? Porque mi familia no se cuenta como nativa, sino migrante en ese Delta del Bravo donde, siglos atrás, deambularon libres los Comecrudo y los Anda el Camino, sería una impostación reclamarlos en mi genealogía personal. Pero, siguiendo la línea de la sangre, sin olvidar nunca la línea del ombligo - la filiación y sucesión femenina - me he encontrado, luego de muchos años de recorridos, con lo que busco: a los guachichiles del altiplano potosino antes de ser asimilados por los tlaxcaltecas, antes de que una serie de negociaciones a las que le llamaron la compra de la paz diera por terminadas las grandes guerras chichimecas a inicios del siglo XVII. ${ }^{12}$

Desde ahí, desde ese flujo que se esparce entre las capas de experiencia material, es cada vez menos posible leer el mestizaje, incluso el mestizaje de la nueva mestiza, como un concepto meramente metafórico. En Borderlands, Anzaldúa liga el mestizaje como concepto a un proceso histórico que, desde su punto de vista, es bestial e inmediato, el resultado carnal y demográfico de la conquista. Sin embargo, México era otra vez un país de mayoría indígena para los años en que se independizó de España a inicios del siglo XIX. El mestizaje, luego entonces, es un hecho menos tajante e inmediato, y más un largo en el que ha sido fundamental el racismo y la marginalización del estado mexicano, que, al menos en el caso de mi familia, no se completó cabalmente sino hasta inicios del siglo XX, a través de ese borramiento racial que con frecuencia acompaña a las largas andanzas de la migración. Tienen razón Yasnaya Aguilar y Mardonio Carballo, activistas y escritores, hablantes del mixe y nahua respectivamente, cuando insisten en que el concepto de mestizaje ha servido para ocultar, o incorporar en su forma borrada o invisible, a la presencia indígena. Carballo añade en una entrevista con El Universal: "El México mestizo, el México de la raza de bronce, el que habla castellano, el que es heterosexual, el México católico, el del Himno Nacional, tiene que desandar sus pasos para ponerse frente a un espejo gigante y ver el rostro que de verdad tiene". ${ }^{13}$ Tal vez nuestra tarea ahora en este sentido sea escarbar desde nuestro propio territorio de enunciación hacia abajo, capa tras capa, hasta encontrar ese punto de fuga indígena desde el cual podremos hablar con nuestra propia Coatlicue.

\footnotetext{
${ }^{12}$ Una versión completa de esta historia puede consultarse en Autobiografía del algodón (Random House, 2020).

${ }^{13}$ Entrevista con Mardonio Carballo, "El mestizaje que creó el nacionalismo es pernicioso", El Universal, Mayo 10, 2019.
} 


\section{LA TERMO}

Cruzamos por el puente Los Tomates antes del mediodía. Mi madre se había quedado a convivir con sus hermanas en Brownsville y nosotros decidimos ir al otro lado para visitar las tumbas de mis abuelos en el cementerio de Santa Rosalía, a unos cuantos kilómetros del Poblado Anáhuac. Las indicaciones precisas que me envió un primo por mensajes de texto nos ayudaron a evadir el enjambre de calles de Matamoros y encontrar, de entre todas las salidas posibles, la que nos llevó al Sendero Nacional, la carretera de dos carriles que une a Matamoros con Valle Hermoso desde hace más de 70 años. No me habías dicho que todo esto era tan hermoso, dijo Saúl. Y yo, extrañada, me volví a ver el paisaje con sus ojos. Del otro lado de las ventanillas empolvadas los verdes lucían espectaculares entre los surcos que se abrían a ambos lados del camino $\mathrm{y}$, los diques que conectaban un sistema de irrigación en pie desde fines de los 1930s, todavía llevaban un agua algo turbia pero mansa a su destino. Los colores ocres de la tierra daban la sensación de que estábamos, ahora sí, fuera de la ciudad. Esto era el campo. Tenía muchos años de no poner pie en esta esquina del país, pero en esta ocasión, gracias a los ojos fuereños de Saúl, la tierra donde nací me pareció genuinamente hermosa.

Apenas si recordaba cómo llegar al panteón de Santa Rosalía, el primero que se estableció un poco después de la colonización que se llevó a cabo a partir de 1937. El cadáver de mi abuela paterna ocupó la tercera tumba del lugar, señalada en ese entonces con una cruz de madera donde casi no se reconoce su nombre y, más recientemente, con un barandal que ya se ha oxidado. Unos 10 años después, enterraron ahí, aunque no a su lado, a mi abuelo paterno. Y ahí ese encuentran también los restos de una tía que murió de cáncer y su esposo, que alguna vez fue carpintero. Hay huizaches y mezquites a su alrededor, flores de anacahuita. Vamos a estar mucho tiempo enterrados, dijo Rulfo. Y tenía razón. La paciencia de los muertos es infinita. No habríamos llegado al panteón sin la ayuda de otro primo que se ofreció a guiarnos por entre las brechas. ¿Qué es eso?, le pregunté apenas si nos bajamos del coche en la primera parada. A lo lejos, una aparatosa construcción de torres dispares y luces prendidas interrumpía el horizonte verde de las parcelas. Un amasijo de cables se arremolinaba entre las chimeneas que, a esa hora de la media tarde, escupían un humo grisáceo, apenas un poco más claro que las nubes que colgaban tímidamente del cielo. Parece una cosa del futuro, murmuró Saúl todavía con las manos sobre el volante. No necesariamente una ciudad. Era algo extraño, totalmente fuera de lugar en el campo. Es la termo, dijo Diego, mi primo. La termoeléctrica, añadió cuando nuestros rostros le pidieron una explicación. Se había instalado ahí ya hace años, durante el sexenio de Zedillo, sin darle una explicación a nadie. Lo cierto era que detrás de las altas paredes que protegían el interior de las miradas ajenas se producía la electricidad que mandaban directamente al otro lado. Los muros no mostraban el nombre de la compañía ni señas de asociación alguna con la Comisión Federal de Electricidad, así que supusimos que sería una compañía privada, de capital extranjero. No sólo se quedan con nuestra agua, continuó Diego viendo hacia la planta, por la que no pagan nada. Además, todo mundo sabe que todo eso produce cáncer. Si la región había sido azolada por la presencia del narco, que cobraba derecho de piso a los agricultores locales, los numerosos casos de cáncer que, según las autoridades, aumentaron un 300\% en la última década, habían convertido a la geometría que componían Matamoros, Valle Hermoso y Anáhuac en el triángulo de la muerte.

Seguramente ninguno de los que llevaban ya tantos años enterrados bajo la tierra del Santa Rosalía imaginaron un futuro así. Los rodeaba la presencia escueta de los árboles, el sonido pasajero de algunas aves y, sobre todo, la sombra de esa máquina monstruosa que consumía silenciosa pero ineluctablemente los recursos de la tierra y los cuerpos mismos de sus habitantes. 
¿De qué otra cosa podríamos hablar con nuestros muertos sino de este presente ominoso en que la producción de electricidad significaba una pena de muerte, dosificada pero segura, para toda la localidad? Dejamos un par de manzanas al ras de las tumbas y, cabizbajos, partimos otra vez. Esto también era la frontera: un lugar donde ni los muertos podían estar a salvo de morir otra vez.

\section{MAY WE SEIZE THE ARROGANCE TO CREATE OUTRAGEOUSLY}

Sólo los panteones famosos, como los más representativos de París, muestran a la entrada un mapa con la localización de los nichos sus difuntos. En la mayoría de los camposantos que, al menos desde el siglo XIX, se colocan a las afueras de las ciudades o pueblos, no hay otra indicación para merodear entre los lotes rectangulares de las tumbas más que las veredas de tierra que otros pasos han ido marcando con el tiempo. Resulta difícil orientarse entre sus pasadizos y sus atajos, sobre todo la primera vez. Llegamos al cementerio Valle de la Paz, en el condado de Hidalgo, a eso de las tres de la tarde, cuando los rayos del sol eran verdaderamente inclementes y todo parecía vibrar sin control bajo su influjo. No queríamos dejar el sur de Texas sin visitarla. Repartimos el cementerio en dos creando una línea imaginaria que pasaba por el centro $\mathrm{y}$, sin hablar mucho, nos dimos a la tarea de buscar su nombre. Este método, que tiene el defecto de requerir de mucho tiempo, también tiene la virtud de ofrecer una especie de radiografía de la comunidad que lo habita: en esos primeros recorridos aprendimos que generaciones enteras de Anzaldúa han poblado la región aledaña a Valle de la Paz al menos desde mediados del siglo XIX. Había mujeres y hombres Anzaldúa; niños Anzaldúa; pequeñas fotos ovaladas, cuarteadas ya por el tiempo, de rostros de Anzaldúa. A las orillas del panteón, enfrentando una tupida hilera de mezquites del otro lado de una malla de alambre, la tumba de Gloria Anzaldúa se dejaba reconocer de lejos por la cantidad y el colorido de las ofrendas. Un collar de flores de papel en llamativos colores naranja y amarillo rodeaba los pies de la virgen que, sobre el filo de la lápida y con las manos juntas, conminaba al rezo. Viejas veladoras llenas ya de lodo seco, cráneos de neón, y ramos de flores de plástico rodeaban también la base de la lápida sobre cuya superficie se leía un verso de la oración ritual con la que termina Light in the Dark / Luz en lo oscuro. Rewriting Identity, Spirituality, Realityel libro que, hasta el último momento, Gloria Anzaldúa imaginó como la disertación con que obtendría el doctorado por parte de la Universidad de California Santa Cruz (el cual recibió, por cierto, de manera póstuma).${ }^{14}$ May we seize the arrogance to create/ outrageously/ sonar wildlyfor the world becomes as/ we dream of it. No fue sino hasta después, cuando revisé el libro del que se extrajo la cita, que me di cuenta de por qué había sido tan difícil entender la frase de inmediato. La $n$ en la lápida carecía de la tilde que la volvía $\tilde{n}$ en el verso original. ${ }^{15}$ Soñar wildly, eso decía el original. Otra travesura de Nepantla. Una señal más de que nos encontrábamos, sin duda, en la frontera.

Habíamos dejado a mi madre en el aeropuerto de Reynosa, esperando con ella hasta que su avión pudo partir después de un atraso de unas 4 horas debido a la niebla. La separación me revolvió algo iridiscente en el pecho y, para evitar el llanto, me dediqué a observar el paisaje que hasta hace muy poco nunca habría descrito como hermoso. Avanzamos por el lado mexicano de la frontera, recorriendo con calma ese brazo con que Tamaulipas se desgaja del golfo y reposa, casi sin querer, a lo largo de las riberas del Río Bravo. Por consejo de mi primo Diego evitamos ir

\footnotetext{
${ }^{14}$ Gloria Anzaldúa, Light in the Dark / Luz en lo oscuro. Rewriting Identity, Spirituality, Reality, ed. AnaLouise Keating (Duke University Press, 2015).

${ }^{15}$ Anzaldúa, Light in the Dark, 157.
} 
hasta Matamoros y cruzamos por el puente de Los Indios que, nos aseguró, era el que siempre tenía menos colas. Así fue. Un oficial de inmigración cubierto de sudor nos dijo abiertamente que el sistema le decía que habíamos cruzado varias veces la línea esos días: de allá para acá, de acá para allá, y de vuelta todo otra vez. ¿Por qué?, nos preguntó. Cuando le dije la verdad, que habíamos venido a dejar a mi madre al aeropuerto para que tomara el avión que la llevaría de regreso a casa, la explicación le pareció habitual. No tardamos más de quince minutos en pasar. Por eso, y porque nos lo habíamos prometido ya varias veces, seguimos las instrucciones del GPS para encontrar ese cementerio donde enterraron el cuerpo de Gloria Anzaldúa un 14 de marzo del 2004.

Mi tía Santos, que regresaba con nosotras, silenciosa en el asiento de atrás, caminó con dificultad entre las tumbas, arrastrando un poco su pie derecho, pero el sol no la amedrentó. Mientras, Lara se enfrentó a ladridos cada vez más alarmantes contra un perro de dimensiones descomunales desde la protección que le ofreció la parte de abajo del auto. Era valiente, pero no tonta. Un hombre de ralos cabellos grises se apareció unos minutos después, sujetando una vara en la mano izquierda. Pensé que se trataba del vigilante del panteón. Algo dijo. Algo volvió a decir. Le pedí, esa segunda vez, que lo repitiera otra vez. Por favor. No estaba segura de si hablaba inglés o español, o el idioma de los difuntos, pero a medida que se aproximaba cobré conciencia de que estábamos absolutamente solos en un cementerio en el sur más profundo de Texas. No sabía si estábamos infringiendo alguna regla o si el hombre simplemente deliraba de calor. Tartamudeé un poco al explicarle que buscábamos la tumba de Gloria Anzaldúa y, cuando sonrió al escuchar el nombre, dejé de sentir miedo y empecé a sentir curiosidad. El viejo se detuvo frente a mí y se señaló el pecho al repetir la palabra Anzaldúa. ¿Usted también es un Anzaldúa?, le pregunté. Confirmó que así era inclinando la cabeza ¿Conoció a Gloria?, continué, esperanzada. Con palabras en inglés y en español, y en alguna combinación que no era spanglish sino otra cosa más, algo de suyo intransferible, el hombre dio a entender que habían compartido mesabanco en la escuela. ¿En la primaria?, volví a preguntar. La carcajada que soltó hizo piruetas en el aire mientras Lara volvía a arreciar la marcha de sus ladridos. Dijo algo más que no pude oír bien. Y luego lo repitió. Sus encías sin dientes volvieron a amedrentarme; la corbata que se había anudado encima de una camiseta neja, de rayas horizontales ya muy deslucidas; las uñas sucias. Luego, abandonando la charla de improviso, elevó la mano derecha, rozando una y otra vez la punta del dedo gordo y el dedo índice. ¿Dinero?, le pregunté. Volvió a abrir la boca como para decir algo y, en el último momento, cambió de opinión. Alcancé a entender que tenía hambre; luego supuse que también tenía sed. Poco a poco, todavía paladeando una jerga que no lograba entender del todo, el hombre se alejó. Avanzó por el camino central del panteón y, pronto, desapareció bajo la luz. ¿Lo viste?, le pregunté a Saúl. ¿A quién?, me preguntó.

Gloria Anzaldúa nunca rechazó el caos y, en lo que AnaLouise Keating denomina como su ontología materialista abierta a la presencia de lo espiritual, las rajaduras y la desintegración ocuparon siempre lugares privilegiados. Su teoría de la Coatlicue sugería, por ejemplo, que el caos producto del desmembramiento de la psique, que involucraba una crítica radical del yo, era la única manera de avanzar por el proceso de sanación que, eventualmente, y trabajo de activismo espiritual de por medio, conduciría a la sensación de completud y de profunda interrelación con el mundo. No por nada ese trabajo filosófico y terapéutico que es Luz en lo oscuro termina (mejor dicho: hace una pausa) con un capítulo sobre el conocimiento-sobre el camino hacia el conocimiento a través del trabajo íntimo y el performance puntual de actos compartidos y públicos-y, otra vez no por nada, ese capítulo concluye con un ritual en el que la autora, volviendo el rostro a los cuatro puntos cardinales, invoca a través de la palabra - de la oración o las oraciones, 
en su sentido sagrado y gramatical— los poderes del aire, agua, tierra y fuego para "incrementar la conciencia espiritual, reconocer nuestra situación de interrelación, y continuar con el trabajo de transformación". ${ }^{16}$ Aptamente, las líneas que quedaron grabadas en su lápida le corresponden a la invocación del fuego que Anzaldúa propone cuando se mira hacia el sur. May we seize the arrogance to create/ outrageously/sonar wildly - for the world becomes as/we dream of it.

Tanto el sustantivo arrogance como el adverbio outrageously son palabras nepantleras, para utilizar un adjetivo de corte netamente anzaldúano: ambas tienen connotaciones positivas y negativas dependiendo del contexto en que se enuncien. Un arrogante puede ser un soberbio, pero también un valiente. La traducción al español de outrageous va desde la indignación hasta lo meramente extravagante, desde lo horrible hasta lo escandaloso o muy llamativo. Pasado por el rasero de clase, ha sido fácil denominar a la arrogancia de los miembros de familias poderosas como mera confianza en sí mismos, y altanería a cualquier transgresión por parte de los hombres y mujeres de las clases trabajadoras. Un hombre arrogante puede ser considerado como brioso o gallardo, pero rara vez una mujer. ¿Necesitamos, pues, hacernos de la arrogancia, reclamar a la arrogancia de los poderosos, para crear así de manera irreverente, arriesgada, transgresora? Anzaldúa nos dice que sí. La vida de Gloria Anzaldúa nos muestra que sí. Para las niñas que crecieron en las ardientes tierras del Río Grande Valley a mediados del siglo XX era eso o una vida de fingida humildad y rabia contenida. Para las jóvenes que, como ella, se fueron de casa y se volvieron andariegas, levantando toda clase de chismes y admiración en el camino, era eso o una vida de discreto pasar, de callada resignación ante el susto que produce, todavía ahora, la sombra del racismo, la homofobia y la marginalización. ¿Qué otra cosa es ese Borderlands que tomó por sorpresa a la academia gringa, colocando las banderas de su propia conquista en campos tan distintos como la filosofía y la historia, la arqueología y la terapéutica, sino un gesto de arrogancia, un trazo de fundamental irreverencia, al que nadie ha podido ningunear, ni mucho menos poner en su lugar, por ya casi tres décadas? Se puede estar de acuerdo o no con sus principios y procesos, pero nadie que piense la frontera puede darse el lujo ahora de no pasar primero por el Nepantla que construyó una muchacha del sur de Texas. Tal vez la ausencia de la tilde sobre la $n$ en su lápida no fue un error, sino una puerta. Tal vez el objetivo entonces, como ahora, es sonar, hacer sonar, reverberar, volverse eco, aumentar el volumen de su voz que son muchas voces, para que ese sueño de sanación devenga mundo, y viceversa.

\footnotetext{
${ }^{16}$ El capítulo seis al que hago referencia aquí se titula "Now Let Us Shift... Conocimiento, Inner Work, Public Acts", 156.
} 